\title{
PERILAKU KESEHATAN RONGGA MULUT TERHADAP KEJADIAN PERIODONTITIS KRONIS PADA PENGGUNA NARKOBA
}

\author{
Tety Verianti' ${ }^{1)}$, Rico Januar Sitorus ${ }^{2)}$, Yuanita Windusari ${ }^{3)}$ \\ ${ }^{1,2,3}$ Program Studi Ilmu Kesehatan Masyarakat, Fakultas Kesehatan Masyarakat \\ Universitas Sriwijaya
}

E-mail: tety.verianti@gmail.com

\begin{abstract}
Problems:The prevalence of drug abuse is increasing globally. Drug abuse is a public health problem that impacts on general and oral health, such as chronic periodontitis. The Aim Of The Research:The aim of this study is to evaluate the association between oral health behaviour, consists of oral hygiene, brushing frequency, and dental visit, with chronic periodontitis in drug abuser. Research Method: The design of this study was an observational study with cross-sectional design. Sampling was conducted with simple random sampling and total sample of 147 people. Data analysis using chi-square test.The Results:The result of this study reports that oral hygiene (p-value 0,000; OR = 96,84;95\% CI 21,58-434,66) and brushing frequency ( $\mathrm{p}$-value 0,035 ; OR = 8,$39 ; 95 \%$ CI 1,08-65,55) were associated with chronic periodontitis in drug abuser. But there is no association between dental visit ( $\mathrm{p}$-value 0,127; OR $=1,84 ; 95 \%$ CI 0,91-3,72) and chronic periodontitis in drug abuser.Conclusions: Oral hygiene and brushing frequency were associated with chronic periodontitis in drug abuser that caused of drug abuser was neglected oral health and did not brush their teeth frequently and meanwhile dental visit was not associated with chronic periodontitis in drug abuser, it was important to do to maintain their good oral health.
\end{abstract}

Keywords :Chronic Periodontitis, Narcotic, Oral Health Behaviour

\begin{abstract}
ABSTRAK
Permasalahan: Prevalensi penyalahgunaan narkoba telah meningkat secara global. Penyalahgunaan obat ini dapat menjadi permasalahan kesehatan masyarakat karena dampaknya bagi kesehatan umum dan rongga mulut, seperti periodontitis kronis.Tujuan Penelitian:untuk mengevaluasi hubungan perilaku kesehatan rongga mulut, yang terdiri dari kebersihan mulut, frekuensi menyikat gigi, dan riwayat kunjungan ke dokter gigi, terhadap kejadian periodontitis kronis pada pengguna narkoba.Metode Penelitian:Desain penelitian ini merupakan penelitian observasional dengan desain cross sectional.Pengambilan sampel dilakukan secara acak dengan jumlah sampel sebanyak 147 orang.Analisis data menggunakan uji chi-square.Hasil: Penelitian menunjukkan terdapat hubungan antara kebersihan mulut (p-value 0,000; OR $=96,84 ; 95 \%$ CI 21,58-434,66) dan frekuensi sikat gigi ( $\mathrm{p}$-value 0,$035 ; \mathrm{OR}=8,39 ; 95 \%$ CI $1,08-65,55$ ) dengan kejadian periodontitis kronis pada pengguna narkoba. Namun tidak terdapat hubungan antara riwayat kunjungan ke dokter gigi dengan kejadian periodontitis kronis pada pengguna narkoba (p-value 0,127; OR $=1,84$; 95\% CI 0,91-3,72). Kesimpulan:Kebersihan mulut dan frekuensi menyikat gigi memiliki hubungan dengan kejadian periodontitis kronis pada pengguna narkoba yang disebabkan karena pengguna narkoba cenderung mengabaikan kesehatan mulut dan tidak menyikat giginya secara rutin yang mengakibatkan terjadinya akumulasi plak dan meskipun riwayat kunjungan ke dokter gigi tidak berhubungan, namun penting dilakukan untuk menjaga kesehatan rongga mulut yang baik.
\end{abstract}

Kata Kunci :Narkoba,Perilaku Kesehatan Rongga Mulut, Periodontitis Kronis 


\section{PENDAHULUAN}

Penggunaan narkotika dan obat-obat terlarang (Narkoba) masih menjadi masalah yang banyak terjadi. Hingga tahun 2017, diaporkan bahwa 5,6\% penduduk di duna menggunakan narkoba dan pada tahun 2019 sebanyak 35 juta penduduk di dunia telah melakukan penyalahgunaan narkoba (UNODC, 2019). BNN melaporkan bahwa 1,8\% penduduk Indonesia merupakan pengguna narkoba di tahun 2019 dan Sumatera Selatan merupakan salah satu wilayah dengan kasus narkoba terbesar. Hingga bulan Desember 2018, telah terdapat 7.039 narapidana dan tahanan dengan kasus narkoba di Sumatera Selatan (BNN, 2019).Angka penyalahgunaan narkoba yang masih tinggi menjadi dapat menjadi masalah kesehatan di masyarakat. Penyalahgunaan narkoba dalam waktu yang lama dapat menyebabkan terjadinya masalah kesehatan, seperti meningkatkan resiko terjadinya penyakit jantung, gangguan pernafasan, hepatitis, HIV, serta gangguan kesehatan gigi dan mulut.Gangguan kesehatan gigi dan mulut akibat penggunaan narkoba diantanya adalah karies gigi, infeksi mukosa, dan periodontitis kronis (Antoniazzi et al., 2016).

Periodontitis kronis ialah infeksi bakteri dari plak pada jaringan periodontal dengan gambaran klinis berupakehilangan perlekatan gingiva, adanya poket, dan mobilitas gigi. Penelitian mengenai pengaruh penggunaan narkoba terhadap jaringan periodontal telah banyak dilakukan.Di China, dilaporkan bahwa kejadian periodontitis kronis ditemukan pada $51,23 \%$ responden pengguna narkoba dan sebanyak 9,26\% dari mereka telah mengalami mobilitas gigi. Dari penelitiannya diketahui hanya $10,11 \%$ subjek yang pernah melakukan kunjungan ke dokter gigi (Ye et al., 2018).Penelitian pada 100 orang pengguna narkoba di Damaskus juga melaporkan prevalensi gangguan periodontal yang tinggi dan $71 \%$ subjek ditemukan memiliki kebiasaan tidak menggosok gigi secara rutin (Al Bush, 2019).Penelitian pada pengguna narkoba di Indonesia menunjukkan sebanyak $77,1 \%$ subjek penelitiannya mengalami periodontitis kronis dengan semua subjek (100\%) dilaporkan memiliki kebersihan mulut yang buruk (Gracia et al.,2014).

Kejadianperiodontitis kronis yang tinggi pada populasi pengguna narkoba dapat terjadi karenadampak langsung dari konsumsi obat-obatanyang menyebabkan keringnya rongga mulut,sistem pertahanan tubuh yang menurun, dan penurunan respon sakit yang tidak dirasakan akibat dari konsumsijenis narkoba tertentu (Shekarchizadeh et al., 2019). Periodontitis kronis juga berkaitan dengan faktor perilaku kesehatan rongga mulut dari pengguna narkoba,seperti buruknya kondisi kebersihan mulut, frekuensi menyikat gigi yang tidak rutin, dan kunjungan ke dokter gigi yang rendah (Sun et al., 2018).Kondisi periodontitis 
kronis yang diabaikan, akan menyebabkanakumulasi plak dan destruksi jaringan periodontal yangberakibat pada gangguan fungsi pengunyahan, fungsi bicara dan estetika estetika (Newman et al., 2012). Atas dasar inilah peneliti ingin meneliti hubungan perilaku kesehatan rongga mulut, yang terdiri dari kebersihan mulut, frekuensi menyikat gigi, dan riwayat kunjungan ke dokter gigi, terhadap kejadian periodontitis kronis pada pengguna narkoba.

\section{BAHAN DAN CARA KERJA}

Penelitian ini merupakan penelitian observasional dengan desain crosssectional.Penelitian dilakukan di Lembaga Permasyarakatan (LP) Kayuagung pada bulan Agustus tahun 2020.Populasi penelitian merupakan warga binaan permasyarakatan dengan kasus narkoba di LP Kayuagung dan sampel penelitian merupakan warga binaan permasyarakatan dengan kasus narkoba.Pengambilan sampel pada penelitian dilakukan secara acak (simple random sampling) yang berjumlah 147 orang.

Data penelitian dikumpulkan melalui dua tahap, yaitu dengan pengisian kuisioner, untuk mengetahui perilaku kesehatan rongga mulut yang terdiri dari frekuensi menyikat gigi dan riwayat kunjungan ke dokter gigi, serta pemeriksaan rongga mulut untuk menilai tingkat kebersihan rongga mulut responden mengunakan indeks oral hygiene index simplified (OHIS) dan menegakkan diagnosa periodontitis kronis menggunakan Indeks Periodontal. Alat dan bahan yang digunakan ialah lembar informed consent, lembar pemeriksaan, lembar kuesioner, alat tulis, alat diagnostik dasar, probe WHO, kapas, alkohol, handscoon, dan masker. Setelah pengumpulan data, dilakukan analisis data yang terdiri dari analisis univariat, yang bertujuan untuk menggambarkan distribusi frekuensi kejadian periodontitis kronis dan karakteristik perilaku kesehatan rongga mulut pada pengguna narkoba dan analisis bivariat yang bertujuan untuk mengetahui hubungan antara perilaku kebersihan rongga mulut dan kejadian periodontitis kronis pada pengguna narkoba.Analisis yang digunakan adalah uji statistik chi-square menggunakan program pengolahan data statistik SPSS versi 20.Data hasil penelitian disajikan dalam bentuk tabel.

\section{HASIL}

Berdasarkan distribusi perilaku kesehatan rongga mulut yang ditunjukkan pada tabel 1, diketahui bahwa sebagian besar responden memiliki kebersihan mulut yang buruk, yaitu sebesar 55,8\%, meskipun sebagian besar responden telah memiliki frekuensi menyikat gigi yang baik $(89,1 \%)$. Dari penelitian ini juga diketahui bahwa sebagian besar responden yang tidak memiliki riwayat kunjungan ke dokter gigi yaitu sebesar $61,9 \%$. Untuk kejadian 
periodontitis kronis dikategorikan menjadi dua kategori, yaitu responden yang mengalami periodontitis kronis dan responden yang tidak mengalami periodontitis kronis. Pada tabel juga terlihat bahwa responden yang mengalami periodontitis kronis ditemukan pada $67,3 \%$ responden dan responden yang tidak mengalami periodontitis kronis sebesar 32,7\%.

Tabel 1.Distribudi Responden Menurut Karakteristik Variabel

\begin{tabular}{lcc}
\hline Variabel & Jumlah & $\begin{array}{c}\text { Persentase } \\
(\%)\end{array}$ \\
\hline Kebersihan Mulut & & 55,8 \\
$-\quad$ Buruk (Skor OHI-S >3) & 82 & 44,2 \\
- Baik (Skor OHI-S $\leq 3)$ & 65 & \\
Frekuensi Menyikat Gigi & & 10,9 \\
- Kurang (<2x sehari) & 16 & 89,1 \\
- Baik ( 2x sehari) & 131 & 61,9 \\
Riwayat Kunjungan ke Dokter Gigi & & 38,1 \\
- Tidak Pernah & 91 & 67,3 \\
- Pernah & 56 & 32,7 \\
Periodontitis Kronis & & \\
- Ya & 99 & 48 \\
\hline
\end{tabular}

Berdasarkan hasil uji statistik yang ditunjukkan di tabel 2, pada alpha 5\% diketahui bahwa terdapat 2 (dua) variabel yang memiliki hubungan bermakna dengan kejadian periodontitis kronis pada pengguna narkoba, yaitu faktor kebersihan mulut ( $p$-value : 0,000 ) dan faktor frekuensi menyikat gigi ( $p$-value : 0,035). Untuk faktor riwayat kunjungan ke dokter gigi, diketahui bahwa tidak terdapat hubungan antara riwayat kunjungan ke dokter gigi dengan kejadian periodontitis kronis pada pengguna narkoba (p-value: 0,127).

Tabel 2.Hubungan Perilaku Kesehatan Rongga Mulut dan Kejadian Peridontitis kronis

\begin{tabular}{|c|c|c|c|c|c|c|c|c|}
\hline \multirow[t]{2}{*}{ Variabel } & \multicolumn{2}{|c|}{ Periodontitis Kronis } & \multicolumn{2}{|c|}{$\begin{array}{c}\text { Tidak } \\
\text { Periodontitis } \\
\text { Kronis } \\
\end{array}$} & \multicolumn{2}{|c|}{ Total } & \multirow{2}{*}{$\begin{array}{c}\text { PR } \\
(95 \% \mathrm{CI}) \\
\end{array}$} & \multirow[t]{2}{*}{ Pvalue } \\
\hline & $\mathbf{n}$ & $\%$ & $\mathbf{n}$ & $\%$ & $\mathbf{n}$ & $\%$ & & \\
\hline \multicolumn{9}{|l|}{ Kebersihan Mulut } \\
\hline Buruk, OHI-S >3 & 80 & 97,6 & 2 & 2,4 & 82 & 100 & 96,842 & 0,000 \\
\hline Baik-Sedang,OHI- & 19 & 29,2 & 46 & 70,8 & 65 & 100 & $(21,576-434,659)$ & \\
\hline \multicolumn{9}{|l|}{$\mathrm{S} \leq 3$} \\
\hline \multicolumn{9}{|l|}{ Frekuensi Sikat Gigi } \\
\hline Kurang, <2x sehari & 15 & 93,8 & 1 & 6,2 & 16 & 100 & 8,393 & 0,035 \\
\hline Cukup, $\geq 2 \mathrm{x}$ sehari & 84 & 64,1 & 47 & 35,9 & 131 & 100 & $(1,075-65,553)$ & \\
\hline \multicolumn{9}{|l|}{$\begin{array}{l}\text { Riwayat Kunjungan } \\
\text { ke Dokter Gigi }\end{array}$} \\
\hline Tidak Pernah & 66 & 72,5 & 25 & 27,5 & 91 & 100 & 1,840 & 0,127 \\
\hline Pernah & 33 & 58,9 & 23 & 41,1 & 56 & 100 & $(0,910-3,719)$ & \\
\hline
\end{tabular}




\section{PEMBAHASAN}

Hasil penelitian ini menunjukkanbahwa kejadian periodontitis kronis pada responden pengguna narkoba lebih banyak terjadi pada responden dengan kebersihan mulut yang buruk $(97,6 \%)$. Hasil uji statistik menunjukkan adanya hubungan yang bermakna antara kebersihan mulut dan kejadian periodontitis kronis $(p$-value $=0,000)$. Hasil ini sejalan dengan penelitian Morio et al.(2008) pada pengguna narkobadi Amerika Serikat yang melaporkan bahwa 96\% responden pengguna narkoba memiliki kondisi kebersihan mulut yang buruk. Penelitian lain oleh Susanto et al.(2020) juga melaporkanadanya hubungan antara kebersihan mulut dan kesehatan jaringan periodontal, dimana subjek dengan kebersihan mulut yang buruk juga diketahui memiliki kondisi jaringan periodontal yang buruk. Hal ini dapat disebabkan karena pada kondisi kebersihan mulut yang buruk akan terjadipeningkatan jumlah bakteri di jaringan periodontal yang mengeluarkan produk metabolik penyebab kerusakan jaringan periodontal.

Penelitian lain oleh Ma et al. (2012) pada pengguna narkoba di China menunjukkan 96,63\% kebersihan mulut respondennya buruk dan kejadian periodontitis kronis ditemukan pada 33\% responden. Hal ini disebabkan karena pengguna narkoba tidak melakukan kunjungan ke dokter gigi secara rutin untuk memeriksakan kondisi rongga mulutnya dan pola hidup yang kacau menyulitkan mereka untuk mempraktikkan perilaku pembersihan rongga mulut dengan baik.Kebersihan mulut yang buruk pada pengguna narkoba juga mungkin disebabkan karena rendahnya kesadaran mereka untuk menjaga kesehatan rongga mulut.Pengguna narkoba biasanya akan cenderung mengabaikan kebersihan rongga mulut karena dampak penggunaan obat yang menyebabkan adanya gangguan fungsi motorik sehingga menyulitkan seseorang untuk membersihkan rongga mulutnya (Saini et al., 2013). Hal ini dapat berdampak pada terjadinya akumulasi plak, terutama di bagian servikal gigi, yang merupakan penyebab utama terjadinya periodontitis kronis (Molendijk et al., 1995).

Pada penelitian ini juga diketahui bahwa kejadian periodontitis kronis pada resonden pengguna narkoba yang menyikat gigi kurang dari 2x sehari ialah sebesar 93,8\% dan terdapat hubungan yang bermakna antara frekuensi menyikat gigi dengan kejadian periodontitis kronis $(p$-value $=0,035)$. Hasil ini sejalan dengan penelitian dilakukan oleh Han \&Park(2017) di Korea yang menunjukkan bahwa terdapat hubungan yang signifikan antara frekuensi menyikat gigi dan kejadian periodontitis kronis. Penyikatan gigi yang tidak rutin merupakan faktor risiko terjadinya periodontitis kronis.Hal ini disebabkan karena menyikat gigi merupakan metode utama untuk membersihkan plak secara mekanis dan mempertahankan kebersihan rongga mulut.Beberapa penelitian menunjukkan bahwa penyikatan gigi yang rutin 
2x sehari, seperti yang dianjurkan oleh asosiasi dental profesi seperti WHO dan FDI, terbukti efektif untuk menjaga kesehatan rongga mulut (Rahardjo et al., 2014).

Namun, selain frekuensi menyikat gigi, durasi dan teknik menyikat gigi juga perlu menjadi perhatian.Penelitian menunjukkan bahwa menyikat gigi selama 2 menit efektif untuk membersihkan seluruh permukaan gigi dan baik untuk kesehatan rongga mulut (Bornstein et $a l ., 2009)$.Sementara itu, untukteknik atau metode menyikat gigi yang bisa digunakan agar didapatkan hasil yang baik diperlukan tidak hanya satu teknik saja melainkan harus dikombinasikan sesuai dengan urutan gigi agar saat menyikat gigi semua bagian permukaan gigi dapat dibersihkan dan tidak merusak lapisan gigi. Oleh sebab itu, meskipun mayoritas responden dalam penelitian ini melaporkan telah rutin menyikat gigi dua kali atau lebih dalam sehari, namun kebersihan rongga mulutnya masih buruk dan ditemukan kejadian periodontitis kronis, dapat dikaitkan dengan durasi menyikat gigi yang belum cukup dan teknik menyikat gigi yang belum tepat.

Sebuah penelitian yang dilakukan oleh Morioet al. (2008) pada pengguna narkoba di Amerika menunjukkan bahwa 39\% responden tidak pernah menyikat gigi dan hanya $6 \%$ dari responden yang menyikat gigi dua kali atau lebih dalam sehari.Penelitian lain oleh Shekarchizadehet al. (2013) pada pengguna narkoba di Iran melaporkan bahwa hanya 13\% dari responden yang menyikat gigi dua kali atau lebih dalam sehari, 39\% dari mereka hanya menyikat gigi satu kali dalam sehari, dan $48 \%$ responden tidak rutin menyikat giginya setiap hari. Rendahnya aktivitas menyikat gigi pada pengguna narkoba ini dapat terjadi karena perubahan perilaku dan suasana hati yang membuat mereka cenderung untuk mengabaikan kebersihan mulutnya.Pada pengguna narkoba juga dapat mengalami gangguan fungsi motorik sehingga menyulitkan mereka untuk menyikat giginya (Saini et al., 2013).

Hasil dari penelitian ini juga menemukan bahwa kejadian periodontitis kronis pada resonden pengguna narkoba yang tidak pernah memiliki riwayat kunjungan ke dokter gigi ialah sebesar 72,5\% dan hasil uji statistik menunjukkan bahwa tidak terdapat hubungan yang bermakna antara riwayat ke dokter gigi dengan kejadian periodontitis kronis ( $p$-value= 0,127). Hal ini tidak sejalan dengan penelitian yang dilakukan oleh Akhteret al. (2008) yang menyatakan adanya hubungan bermakna antara kunjungan ke dokter gigi dan kejadian periodontitis. Hasil penelitiannya menunjukkan bahwa kejadian periodontitis pada kelompok responden yang tidak melakukan kunjungan rutin ke dokter gigi ialah sebesar 95,7\% dan kejadian periodontitis pada kelompok responden yang melakukan kunjungan rutin ke dokter gigi ialah sebesar $4,3 \%$. 
Pengguna narkoba merupakan kelompok yang cenderung memiliki riwayat kunjungan ke dokter gigi yang rendah. Dari hasil penilitian yang dilakukan oleh Akhter et al. (2008), melaporkan bahwa sebanyak $46 \%$ pengguna narkoba tidak pernah atau tidak melakukan kunjungan ke dokter gigi dalam setahun terakhir. Dari penelitiannya juga diketahui bahwa $53,4 \%$ dari mereka mengalami gangguan periodontal, dan hanya 18,2\% dari mereka yang melakukan pemeriksaan ke dokter gigi. Pada pengguna narkoba yang tidak melakukan pemeriksaan ke dokter gigi, memiliki lebih banyak permasalahan dalam rongga mulut dibandingkan dengan mereka yang memeriksakan diri ke dokter gigi.Mereka tidak melakukan kunjungan rutin ke layanan kesehatan mulut dan dokter gigi karena rendahnya penghargaan terhadap diri sendiri, adanya perasaan bahwa mereka tidak ada kebutuhan untuk melakukannya, adanya rasa takut merasakan sakit apabila ke dokter gigi, kesulitan biaya dan tidak memiliki waktu untuk melakukannya.Selain itu, adanya pemahaman bahwa kunjungan ke dokter gigi hanya dilakukan apabila terdapat keluhan atau rasa di rongga mulut juga menjadi penyebab utama rendahnya kunjungan ke dokter gigi (Al-Shammari et al., 2007).

Rendahnya kunjungan ke dokter gigi pada pengguna narkoba perlu menjadi perhatian.Karena, seperti yang telah dijelaskan di atas, menjaga kebersihan rongga mulut secara rutin merupakan hal yang penting untuk dilakukan.Namun yang tidak kalah penting adalah melakukan kunjungan rutin ke dokter gigi untuk menjaga kesehatan rongga mulut yang baik dan mencegah terjadi permasalahan rongga mulut di kemudian hari.American Dental Association (ADA) dan organisasi kesehatan gigi lainnya telah menyarankan setiap individu untuk melakukan kunjungan dan pemeriksaan ke dokter gigi minimal setiap enam bulan. Kunjungan ini dilakukan untuk mendapatkan pelayanan diagnostik dan profilaktik sebagai bentuk pencegahan, dekteksi dini, dan perawatan penyakit di rongga mulut, termasuk periodontitis kronis (Alkhalifa \& Zahran, 2016).

\section{KESIMPULAN}

Berdasarkan hasil penelitian ini dapat disimpulkan bahwa sebagian besar responden pengguna narkoba memiliki kebersihan mulut yang buruk, meskipun sebagian besar responden telah memiliki frekuensi menyikat gigi yang baik, dan sebagian besar responden tidak memiliki riwayat kunjungan ke dokter gigi.Hasil uji statistik menunjukkan adanya hubungan antara faktor perilaku kesehatan rongga mulut, yaitu kebersihan mulut dan frekuensi sikat gigi dengan kejadian periodontitis kronis pada pengguna narkoba, namun riwayat kunjungan ke dokter gigi tidak berhubungan dengan kejadian periodontitis kronis pada pengguna narkoba.Hasil dari penelitian ini diharapkan dapat digunakan sebagai upaya 
pengembangan ilmu pengetahuan dalam bidang kesehatan gigi dan mulut, serta sebagai acuan dalam pelaksanaan penyuluhan kesehatan gigi dan mulut untuk para pengguna narkoba.

\section{UCAPAN TERIMA KASIH}

Ucapan terima kasih penulis sampaikan kepada seluruh pihak yang telah berpartisipasi dalam penelitian ini.

\section{DAFTAR PUSTAKA}

Akhter R, Hassan NM, Aida J, Takinami S, Morita M. 2008.Relationship between betel quid additives and established periodontitis among Bangladeshi subjects. J Clin Periodontol, 35(1):9-15.

Al Bush MM. 2019. An oral cavity profile in illicit- Drug abusers? J Indian Soc Periodontol, 23(6):517-524.

Alkhalifa, NS. \& Zahran, DH. 2016. Reasons Preventing or Delaying Dental Visits in Taibah University Students. BJJMR, 13(11): 1-8.

Al-Shammari KF, Al-Ansari JM, Al-Khabbaz AK, Honkala S. 2007. Barriers to seeking preventive dental care by Kuwaiti adults. Med Princ Pract, 16(6):413-419.

Antoniazzi RP, Feldens CA, Zanatta FB. 2016. Association Between Periodontitis and the Use of Crack Cocaine and Other Illicit Drugs. Journal of Periodontology, 87(12): 1396-1405.

Badan Narkotika Nasional. 2019. Indonesia Drugs Report. Jakarta: Pusat Penelitian Data dan Informasi Badan Narkotika Nasional Republik Indonesia.

Bornstein MM, Kislig K, Hoti BB, Seemann R, Lussi A. 2009. Prevalence of halitosis in the population of the city of Bern, Switzerland: a study comparing self-reported and clinical data. Eur J Oral Sci, 117(3):261-267.

Gracia I, Rensa, Minawati, Hatono TS,Surilena. 2014. Gigi Karies dan Kelainan Jaringan Periodontal pada Pengguna Heroin yang Menjalani Terapi Rumatan Metadon. Damianus Journal of Medicine, 13(3): 191-198.

Han K\&Park JB. 2017. Association between oral health behavior and periodontal disease among Korean adults: The Korea national health and nutrition examination survey. Medicine (Baltimore), 96(7): 1-7.

Ma H, Shi XC, Hu DY, Li X. 2012. The poor oral health status of former heroin users treated with methadone in a Chinese city. Med Sci Monit, 18(4):51-55.

Molendijk B, Horst GT, Kasbergen M, Truin GJ, MulderJ. Dental health in drug and alcohol addicts. Community Dent Oral Epidemiol 1995, 102(8): 296-298.

Morio KA, Marshall TA, Qian F, Morgan TA. 2008. Comparing diet, oral hygiene and caries status of adult methamphetamine users and nonusers: a pilot study. J Am Dent Assoc, 139(2):171-176.

Newman, Carranza, Klokkevold, Takei. 2012. Carranza's Clinical Periodontology 11 th ed. St. Louis: Elsevier.

Rahardjo A, MaharaniDA, KiswanjayaB, Idrus E, Nicholson J, CunninghamPJ, Schafer F. 2014. Measurement of Tooth Brushing Frequency, Time of Day and Duration of Adults and Children in Jakarta, Indonesia.Journal of Dentistry Indonesia, 21(3): 85-88.

Saini GK, Gupta ND, Prabhat KC. 2013.Drug addiction and periodontal diseases. J Indian Soc Periodontol, 17(5):587-591. 
Saini GK, Gupta ND, Prabhat KC. 2013.Drug addiction and periodontal diseases. $J$ Indian Soc Periodontol, 17(5):587-591.

Shekarchizadeh H, Khami MR, Mohebbi SZ, Ekhtiari H, Virtanen JI. 2019. Oral health status and its determinants among opiate dependents: a cross-sectional study. BMC Oral Health, 9(1):5.

Shekarchizadeh H, Khami MR, Mohebbi SZ, Virtanen JI. 2013. Oral health behavior of drug addicts in withdrawal treatment. BMC Oral Health, 13:11.

Sheridan J, Aggleton M, Carson T. 2001. Dental health and access to dental treatment: a comparison of drug users and non-drug users attending community pharmacies. $\mathrm{Br}$ Dent J, 191(8):453-457.

Sun D, Ye T, Ren P, Yu S. 2018. Prevalence and etiology of oral diseases in drug-addicted populations: a systematic review. J Clin Exp Med, 11(7): 6521-6531.

Susanto A, Carolina DN, Amaliya A, Setia PIM, Miranda A. 2020.Periodontal health status and treatment needs of the community in Indonesia: A cross sectional study. Journal of International Oral Heatlh, 23(2): 114-119.

United Nations Office on Drug and Crime. 2019. World Drug Reports. Vienna: United Nations publications.

Ye T, Sun D, Dong G, Xu G, Wang L, Du J, Ren P, Yu S. 2018. The effect of methamphetamine abuse on dental caries and periodontal diseases in an Eastern China city.BMC Oral Health, 18(1): 1-6. 